\title{
TÜVENAN TİNKALDEN KALSİNE TİNKAL ÜRETİMİ
}

\author{
Orhan YILMAZ* \\ *Eti Mine Works, Ayvalı Mah. Halil Sezai Erkut Cad., Afra Sok. No:1/A06010 Etlik-Keçiören/ANKARA \\ orhanyilmaz1038@hotmail.com
}

(Geliş/Received: 03.01.2013; Kabul/Accepted: 23.01.2014)

\begin{abstract}
ÖZET
$\mathrm{Bu}$ çalı̧̧mada yeni bir ürün olan kalsine tinkalin laboratuvar koşullarında üretimi amaçlanmıştır. Eti Maden İşletmeleri Genel Müdürlüğü Kırka Bor İşletme Müdürlüğü bünyesinde üretilmekte olan tinkal cevheri, İșletme bünyesinde bulunan tesislerde boraks pentahidrat üretiminde, Bandırma Bor ve Asit Fabrikalarında ise boraks pentahidrat, boraks dekahidrat ve sodyum perborat üretiminde kullanılmaktadır. Bu çalışmada, tinkal cevherinden kalsine tinkal üretimi amaçlanmıştır. Laboratuvar tipi firınlarda $100-500^{\circ} \mathrm{C}$ 'ler arasında kalsinasyon işlemi gerçekleştirilerek kalsine ürün elde edilmiştir. Kalsine ürün bir değirmende öğütülerek düşük tane boyutlarına indirilmiş ve daha sonra hava klasifikatöründe kalsine tinkalin kilden ayrılmasına yönelik çalışmalar yapılmıştır. $\mathrm{Bu}$ işlemler sonucunda çalışma koşullarına bağlı olarak \%10-15 arasında kil içeren \% 45-55 $\mathrm{B}_{2} \mathrm{O}_{3}$ içerikli kalsine tinkal yaklaşık \%80 verimle elde edilmiştir.
\end{abstract}

Anahtar kelimeler: Tinkal, Kalsine Tinkal, Bor Minerali

\section{PRODUCTION OF CALCINED TINCAL FROM RUN-OF-MINE TINCAL}

\begin{abstract}
In this study there have been a main purpose to product calcine tincal which is a new product. Tincal ore produced in Kurka Boron Works of Eti Mine Works General Management is used in borax pentahydrate production in the same plant and in borax pentahydrate, decahydrate and sodium perborate production in Bandirma Boron and Acid Plants. In this study, it was aimed to produce calcined tincal from tincal ore. Calcination was performed in laboratory type furnaces between $100-500^{\circ} \mathrm{C}$ and calcined tincal was produced. The particle size of the calcined product was reduced by a grinding mill and then calcined tincal was separated from the clay by air classifier. As a result, depending on the working conditions calcined tincal containing between $10-15 \%$ of clay was obtained with a yield of around $80 \%$.
\end{abstract}

Keywords: Tincal, Calcined Tincal, Boron Mine

\section{GIRISS (INTRODUCTION)}

Türkiye bor rezervi olarak Dünyada birinci sırada bulunmaktadır. Türkiye de bor madeni yatakları özellikle Kırka, Emet, Bigadiç, Kestelek' te bulunmaktadır. Eti Maden İşletmeleri Mineral Bazında Rezerv Miktarlarına göre tinkal rezervi \% 24 oranında kolemanitten sonra 2. Sirada yer almaktadır $[1,2]$. Kırka Bor İşletme Müdürlüğünde ortalama \% $25 \mathrm{~B}_{2} \mathrm{O}_{3}$ tenörlü üretilen tüvenan tinkal yaklaşık 30 yıldır konsantratör tesislerinde zenginleştirilmektedir. Burada temel prensip cevherin kırılarak ufalanması ve suyla yikanarak yüzey killerinin cevherden uzaklaştırılması esasına dayanmaktadır. İşlem sonucunda $\% 32 \quad \mathrm{~B}_{2} \mathrm{O}_{3}$ tenörlü konsantre tinkal üretilmektedir. Ancak, konsantre tinkal üretim işlemi esnasında önemli miktarda su kullanılmakta, sonuçta ortaya sulu atık çıkmakta ve bu atıklar ancak atık barajlarında depolanabilmektedir. Konsantrasyon işlemi dışında tüvenan tinkalin zenginleştirilmesine yönelik farklı yöntemler mevcut olup, hali hazırda bu amaca yönelik olarak "çözme oluğu" projesi Kırka Bor İşletmesinde kısmen uygulanmakta ve daha yaygın olarak uygulanmasıyla ilgili çalışmalar da devam etmektedir. Tüvenan tinkalin zenginleştirilmesine yönelik diğer bir proses de kalsinasyondur. Kalsinasyon esnasında tinkal genleşerek şişer $[3,4,5]$. Genleşme işlemi $100^{\circ} \mathrm{C}$ 'nin üzerinde başlar ve $217^{\circ} \mathrm{C}^{\prime}$ ye kadar genleşmenin \%87'si tamamlanır [2] $217^{\circ} \mathrm{C}$ 'ye kadar meydana 
gelen genleşme \%240 civarındadır. Kalsinasyonla beraber meydana gelen genleşme işlemi esnasında tüvenan tinkalin içerdiği kil gibi gang mineralleri tinkal yapısının içine hapsolur. Bu nedenle tinkalin killerden ayrılabilmesi için kalsine tinkalin parçalanarak ufalanması ve daha sonra iç yapıya hapsolmuş killerin serbest hale getirilerek bir şekilde tinkalden ayrılması için seperasyon işleminin yapılması gerekmektedir. Kalsinasyon sonucunda ortaya çıkan atık katı fazda olup, bu katı atıkların atık barajları yerine tumba sahalarında depolanması imkanı mevcuttur. Özellikle son yıllarda çevresel konularda hassasiyetin artması nedeniyle atıkların katı olarak depolanması hem atık bertaraf maliyetini düşürecek hem de çevresel sorunların asgari düzeye indirilmesini sağlayacaktır. Ayrıca, boraks pentahidrat üretiminde daha düşük kil içerikli hammadde kullanılması, üretimde kapasite ve verimin artmasına neden olacaktır.

Bu çalışmada, laboratuar tipi firınlarda tüvenan tinkal kalsinasyon işlemine tabi tutulmuş ve elde edilen kalsine ürün değirmende öğütülerek tane boyutu düşürülmüş ve daha sonra separasyon yoluyla kil, tinkal bünyesinden uzaklaştırılarak yüksek tenörlü kalsine tinkal üretilmiştir $[6,7]$.

\section{MATERYAL VE YÖNTEM (MATERIAL AND METHOD)}

Deneysel çalışmalarda Kırka Bor İşletme Müdürlüğü bünyesinde üretilen tüvenan tinkal kullanılmıştır. Tüvenan tinkal yaklaşı $1,5 \mathrm{~g} / \mathrm{cm}^{3}$ dökme yoğunluğuna sahiptir. Tüvenan tinkalin kimyasal analizi Tablo 1'de verilmektedir. X-1şınları difraksiyon analizinde tüvenan tinkalin, gang mineralleri olarak dolomit, smektit (montmorillonit tipi kil alt grubu) ve kalsit içerdiği tespit edilmiştir
(Şekil 1). Tüvenan tinkal -25 mm boyutuna kırıldıktan sonra laboratuar tipi firınlarda sadece su buharı çıkışına izin veren ağzı kapalı kaplarda yaklaşık $250 \mathrm{~g}$ numuneler konularak $100-500^{\circ} \mathrm{C}$ sicakliklar arasinda kalsinasyon işlemine tabi tutulmuştur. Numunenin firında bekleme süresi 30-40 dakika arasındadır. Elde edilen kalsine numuneler laboratuar tipi bilyalı bir değirmen içerisinde az sayıda bilya ile 20-30 dakika süreyle öğütülmüştür. Öğütülmüş kalsine numunelerin tane boyu $500 \mu$ m'nin altındadır. Kalsine tinkal bünyesinde bulunan kilin ayrilarak tinkalin zenginleştirilebilmesi amacıyla farklı tane boyutundaki numuneler laboratuar tipi pnömatik separatörde ayırma işlemine tabi tutulmuştur. Pnömatik seperatör değişken rotor hızı ve farklı hava debilerinde ayarlanarak çalıştırılabilmektedir.

Tüvenan tinkal ve kalsinasyon sonucunda elde edilen kalsine tinkal ve kilde bor analizleri volumetrik, diğer empüritelerin analizleri ise atomik absorpsiyon spektrofotometrisi (Varian SpectraAA-300) kullanılarak gerçekleştirilmiştir. Ayrıca, tüvenan tinkal ve kalsinasyon sonucunda elde edilen kalsine tinkal ve kil, hem diferansiyel termal analiz ve termogravimetrik analiz cihazı (DTA-TG sistemi, SETARAM Labsys 3.0) hem de X-ışınları difraktometresi (Rigaku, D/Max-2200, CuK $\alpha, 2 \theta=0$ $60^{\circ}$, tarama hızı $=2^{\circ}$ dak $\left.^{-1}\right)$ kullanılarak incelenmiştir.

\section{SONUÇLAR VE TARTIŞMA (RESULTS AND DISCUSSIONS)}

Laboratuar tipi firınlarda kalsine edilen tinkal cevherinin 1sıtıldığında bünyesindeki suyunun açığa çıkması sonucunda genleştiği ve çok yüksek poroziteye sahip bir yapıya dönüştüğü tespit edilmiştir.

Tablo 1. Tinkal Cevherinin Kimyasal Analizi (Chemical analysis of Tincal Ore)

\begin{tabular}{|c|c|c|c|c|c|c|c|c|c|}
\hline$\% \mathrm{~B}_{2} \mathrm{O}_{3}$ & $\% \mathrm{MgO}$ & $\% \mathrm{CaO}$ & $\% \mathrm{SO}_{3}$ & $\% \mathrm{SiO}_{2}$ & $\% \mathrm{Na}_{2} \mathrm{O}$ & $\% \mathrm{Fe}_{2} \mathrm{O}_{3}$ & $\% \mathrm{Al}_{2} \mathrm{O}_{3}$ & $\% \mathrm{H}_{2} \mathrm{O}$ & \% K.K \\
\hline 20,95 & 12,65 & 9,78 & 0,16 & 8,03 & 9,51 & 0,12 & 0,310 & 4,67 & 42,16 \\
\hline
\end{tabular}

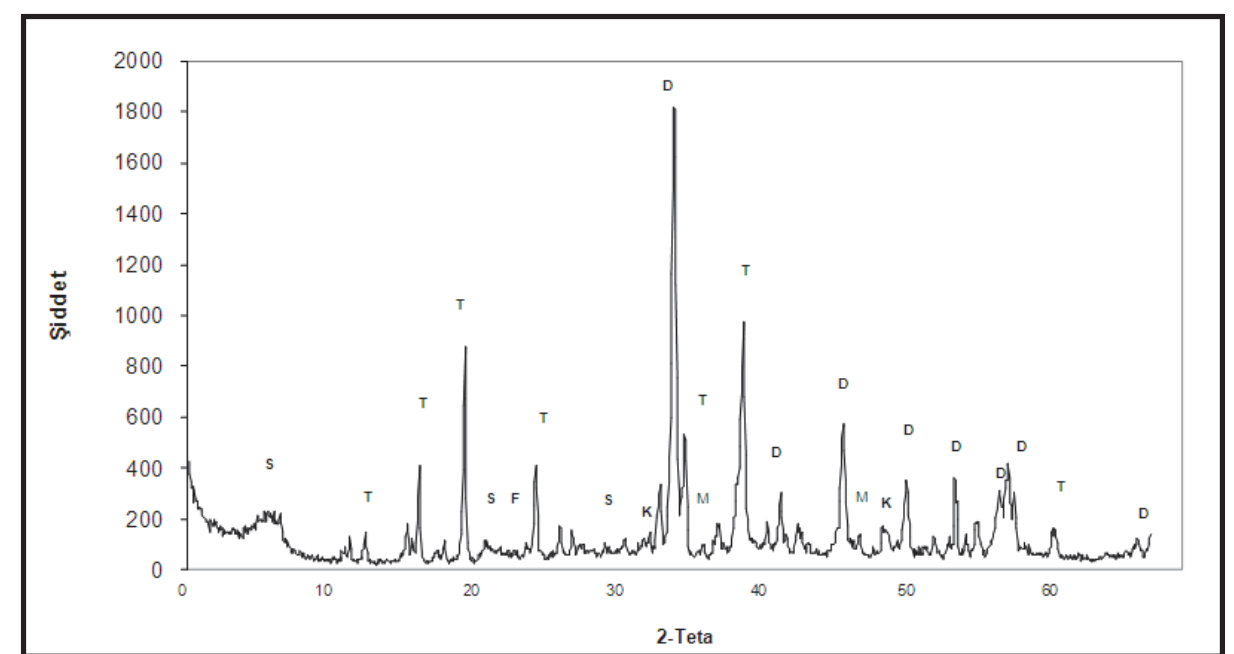

Şekil 1. Tüvenan tinkalin X-ışınları difraksiyonu analizi (T: Tinkal, D: Dolomit, S: Smektit, K: Kalsit). (XRD analysis of Tincal Ore) 


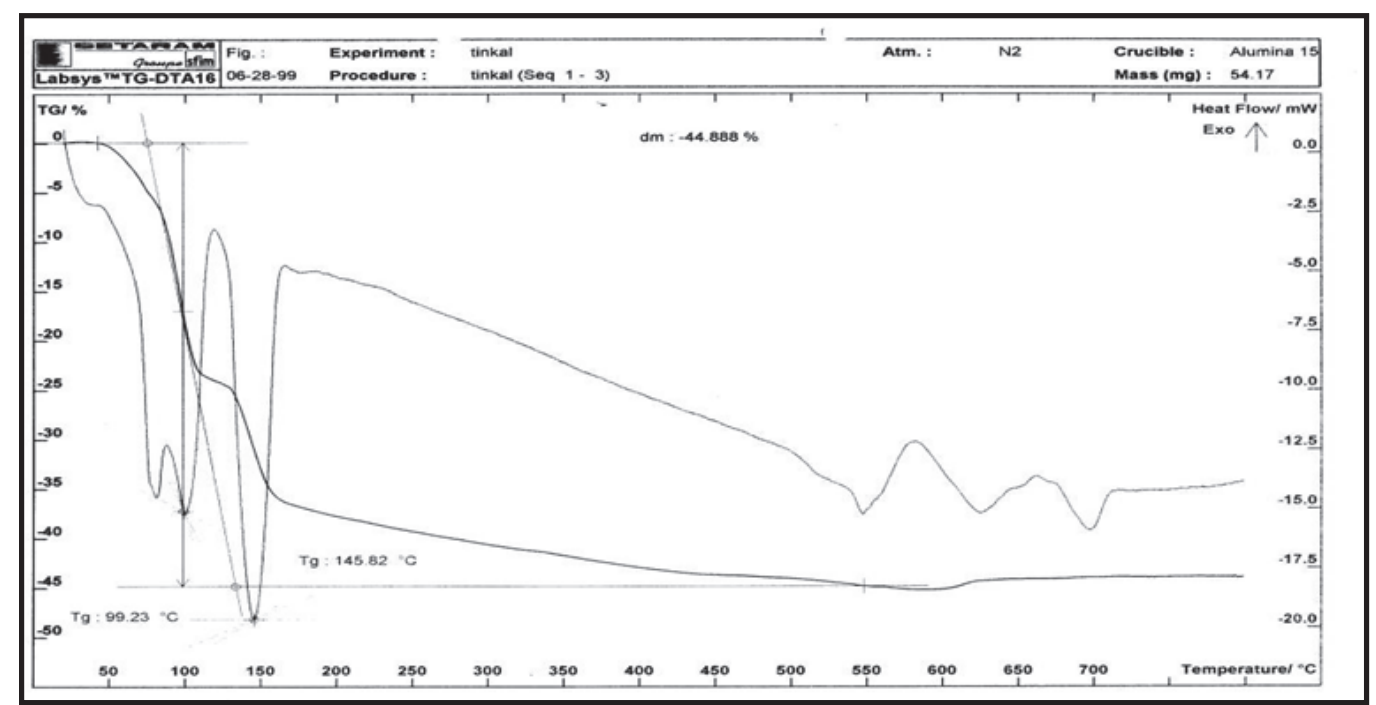

Şekil 2. Tüvenan tinkalin TG-DTA grafiği (TG-DTA analysis of Tincal Ore)

Cevherli kısmın genleşmesi sonucu daha kırılgan ve daha düşük yoğunlukta bir yapı oluşurken, tüvenan tinkal bünyesindeki kil daha sert hale gelmektedir. Tüvenan tinkalin TG-DTA grafiği Şekil 2'de görülmektedir. Tüvenan tinkal $20-600^{\circ} \mathrm{C}^{\prime}$ ler arasinda yaklaşık \%45'lik bir ağırlık kaybına uğramakta ve ağırlık kaybıyla ilişkili olarak 3 tane endotermik pik gözlenmektedir $\left(85^{\circ} \mathrm{C}, 99^{\circ} \mathrm{C}\right.$ ve $\left.146^{\circ} \mathrm{C}\right)$. Saf boraks dekahidratın içerdiği teorik su miktarının $\% 47$ olduğu dikkate alındığında, tinkalin $600^{\circ} \mathrm{C}^{\prime}$ de bünye suyunun büyük çoğunluğunu kaybettiği görülmektedir. $350^{\circ} \mathrm{C}$ 'de oluşan ürünün satışa uygun $\mathrm{B}_{2} \mathrm{O}_{3}$ ve kil oranına sahip olması sonucu bu sicaklıkta elde edilen kalsine ürünün kimyasal analizi ve elek analizi incelenmiştir.

\subsection{Kalsinasyon ve Öğütme (Calcination and Milling)}

Tüvenan tinkal $100-500^{\circ} \mathrm{C}^{\prime}$ ler arasında kalsinasyona tabi tutulmuştur. $350^{\circ} \mathrm{C}^{\prime}$ de elde edilen kalsine ürünün kimyasal analizi ve elek analizi sonuçları Tablo 2 ve Tablo 3'de verilmiştir. Elek analizi sonuçlarından kalsine ürünün $\%$ 46,33'nün $8,80 \mathrm{~mm}$ üzerinde olduğu görülmektedir. Ayrıca tane boyut aralıklarındaki $\mathrm{B}_{2} \mathrm{O}_{3}$ dağılımları da tespit edilerek Tablo 3 'de sunulmuştur. $\% \mathrm{~B}_{2} \mathrm{O}_{3}$ dağılımları incelendiğinde $\quad \mathrm{B}_{2} \mathrm{O}_{3}{ }^{\prime}$ 'ün $\% \quad 20,48$ 'nin $\quad 8,80 \quad \mathrm{~mm}$ üzerinde, \% 44,51'nin ise $0,25 \mathrm{~mm}$ 'nin altında olduğu görülmüştür. $\mathrm{Bu}$ sonuç, kırılgan bir yapıya sahip tinkalin düşük tane boyutlarında yoğunlaştı̆ıını, kalsine kilin ise tinkale göre daha sert olması sebebiyle daha büyük tane boyutlarında kaldığını göstermiştir. Tüvenan tinkalin kalsinasyon aşamasında, laboratuvar tipi kutu firında yaklaşık 2030 dakika kadar ssıl işleme tabi tutulması ile;

$\mathrm{Na}_{2} \mathrm{~B}_{4} \mathrm{O}_{7} \cdot 10 \mathrm{H}_{2} \mathrm{O}$ Is $1 \longrightarrow \mathrm{Na}_{2} \mathrm{~B}_{4} \mathrm{O}_{7} \cdot(1-5) \mathrm{H}_{2} \mathrm{O}+$
$(5-9) \mathrm{H}_{2} \mathrm{O}$ reaksiyonuna uygun olarak kristal suyunun ayrılması sağlanmıştır.

Tablo 2. $350^{\circ} \mathrm{C}^{\prime} \mathrm{de}$ elde edilen kalsine ürünün kimyasal analizi (Chemical analysis of the product obtained calcined at $3500^{\circ} \mathrm{C}$ )

\begin{tabular}{|c|c|c|}
\hline $\mathbf{\% B}_{\mathbf{2}} \mathbf{O}_{\mathbf{3}}$ & \multicolumn{1}{c|}{$\mathbf{N a}_{\mathbf{2}} \mathbf{O}$} & $\mathbf{\%} \mathbf{K} . \mathbf{K}$ \\
\hline 48,34 & 24,39 & $\% 14,72$ \\
\hline
\end{tabular}

$350^{\circ} \mathrm{C}$ 'de kalsine edildikten sonra $500 \mu \mathrm{m}$ 'ye öğütülmüş kalsine üründe seperasyon sonucu $\mathrm{B}_{2} \mathrm{O}_{3}$ kurtarma randımanı \% 80 civarında elde edilen ürün $\mathrm{B}_{2} \mathrm{O}_{3}$, bünye suyu ve safsılzlıklar açısından hedeflenen satışa uygun ürüne yakın özelliklerdedir (Tablo 3, Şekil 3).

Tablo 3. $350^{\circ} \mathrm{C}$ ' de kalsine edilen ürünün elek analizi ve $\mathrm{B}_{2} \mathrm{O}_{3}$ dağ 1 lımları (Grain size of the product calcined at $350^{\circ} \mathrm{C}$ and $\mathrm{B}_{2} \mathrm{O}_{3}$ distributions)

\begin{tabular}{|c|c|c|c|c|c|}
\hline Elek açıklığı & Ăğırlık, $g$ & \% A ğırlık & $\% \mathrm{~B}_{2} \mathrm{O}_{3}$ & $\mathrm{~B}_{2} \mathrm{O}_{3}(\mathrm{~g})$ & $\% \mathrm{~B}_{2} \mathrm{O}_{3}$ Dağılımı \\
\hline$+8,80$ & 467 & 46,33 & 2,12 & 9,90 & 20,48 \\
\hline$-8,80+5,60$ & 203 & 20,14 & 1,85 & 3,76 & 7,77 \\
\hline$-5,60+4,00$ & 117 & 11,60 & 3,22 & 3,77 & 7,79 \\
\hline$-4,00+2,00$ & 102 & 10,12 & 4,90 & 4,99 & 10,34 \\
\hline$-2,00+1,00$ & 26 & 2,58 & 9,10 & 2,37 & 4,89 \\
\hline$-1,00+0,50$ & 11 & 1,09 & 12,12 & 1,33 & 2,76 \\
\hline$-0,50+0,25$ & 6 & 0,60 & 11,68 & 0,70 & 1,45 \\
\hline \multirow[t]{2}{*}{$-0,25$} & 76 & 7,54 & 28,31 & 21,52 & 44,51 \\
\hline & 1008 & 100 & & 48,34 & 100,00 \\
\hline
\end{tabular}




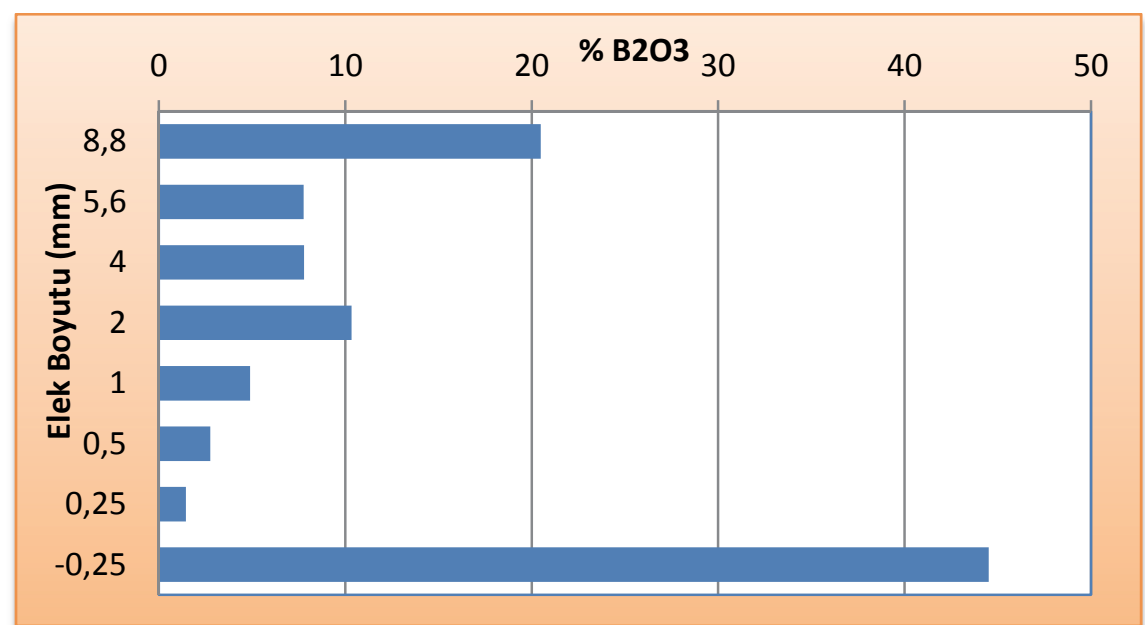

Şekil 3. $350^{\circ} \mathrm{C}$ 'de Kalsine Ürünün Elek Analizi ve $\mathrm{B}_{2} \mathrm{O}_{3}$ Dağılım Grafiği (Grain size of the product calcined at $350{ }^{\circ} \mathrm{C}$ and $\mathrm{B}_{2} \mathrm{O}_{3}$ distributions)

Seperasyon açısından önemli olması sebebiyle 350 ${ }^{\circ} \mathrm{C}$ 'de kalsinasyon sonucunda elde edilen kalsine tinkal ve kalsine kilin dökme yoğunlukları hesaplanmıştır. $\quad-250 \mu \mathrm{m}$ ebatındaki dökme yoğunluğunun kalsine tinkal için ortalama $0,40 \mathrm{~g} / \mathrm{cm}^{3}$, kil için ise ortalama $1,00 \mathrm{~g} / \mathrm{cm}^{3}$ seviyelerinde olduğu görülmüştür.

\subsection{Separasyon İşlemi (Separation Process)}

Kalsinasyon işlemi sonucunda elde edilen kalsine ürünün zenginleştirilmesi diğer bir ifadeyle tinkal cevheri bünyesindeki kilin uzaklaştırılması amacıyla, tinkal ve kil arasındaki yoğunluk ve tane boyutu farkından yararlanılmıştır. Kalsinasyon işleminden

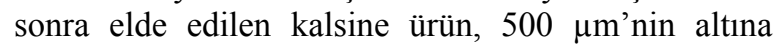
ögütüldükten sonra seperasyon işlemi gerçekleştirilmiştir. Farklı sıcaklıklarda kalsine edilerek, ögütülen ve laboratuar tipi pnömatik seperatörde ayırma işlemine tabi tutulan kalsine tinkalin kimyasal analizi Tablo 4'de verilmiştir. Beklendiği gibi sıcaklık yükseldikçe kalsine tinkalin $\mathrm{B}_{2} \mathrm{O}_{3}$ ve $\mathrm{Na}_{2} \mathrm{O}$ içerikleri yükselmekte ancak diğer empüriteler açısından numuneler arasında önemli bir farklılık olmadığı görülmektedir (Tablo 3, Şekil 3).

Tablo 4. Farklı Sıcaklılarda kalsine edilen Tüvenan tinkalin öğütme ve seperasyon işlemine tabi tutulduktan sonraki kimyasal analizleri (Chemical analyses of calcined tincal after grinding and seperation)

\begin{tabular}{|c|c|c|c|c|c|c|c|c|c|}
\hline Numune & $\% \mathrm{~B}_{2} \mathrm{O}_{3}$ & $\% \mathrm{MgO}$ & $\% \mathrm{CaO}$ & $\% \mathrm{SO}_{3}$ & $\% \mathrm{SiO}_{2}$ & $\% \mathrm{Na}_{2} \mathrm{O}$ & $\% \mathrm{Fe}_{2} \mathrm{O}_{3}$ & $\% \mathrm{Al}_{2} \mathrm{O}_{3}$ & \%K.K \\
\hline $100^{\circ} \mathrm{C}$ & 32,35 & 5,28 & 4,26 & 0,15 & 5,38 & 9,89 & 0,05 & 0,18 & 39,57 \\
\hline $200^{\circ} \mathrm{C}$ & 43,56 & 5,34 & 4,46 & 0,14 & 4,68 & 17,67 & 0,05 & 0,14 & 22,91 \\
\hline $300^{\circ} \mathrm{C}$ & 44,44 & 5,31 & 4,81 & 0,09 & 4,34 & 25,17 & 0,05 & 0,11 & 15,03 \\
\hline $350^{\circ} \mathrm{C}$ & 48,34 & 5,29 & 5,01 & 0,08 & 4,28 & 24,39 & 0,05 & 0,11 & 14,72 \\
\hline $400^{\circ} \mathrm{C}$ & 50,05 & 4,89 & 5,6 & 0,08 & 4,19 & 26,19 & 0,05 & 0,12 & 14,32 \\
\hline $500^{\circ} \mathrm{C}$ & 54,01 & 4,98 & 5,71 & 0,09 & 4,03 & 25,98 & 0,06 & 0,10 & 9,34 \\
\hline
\end{tabular}

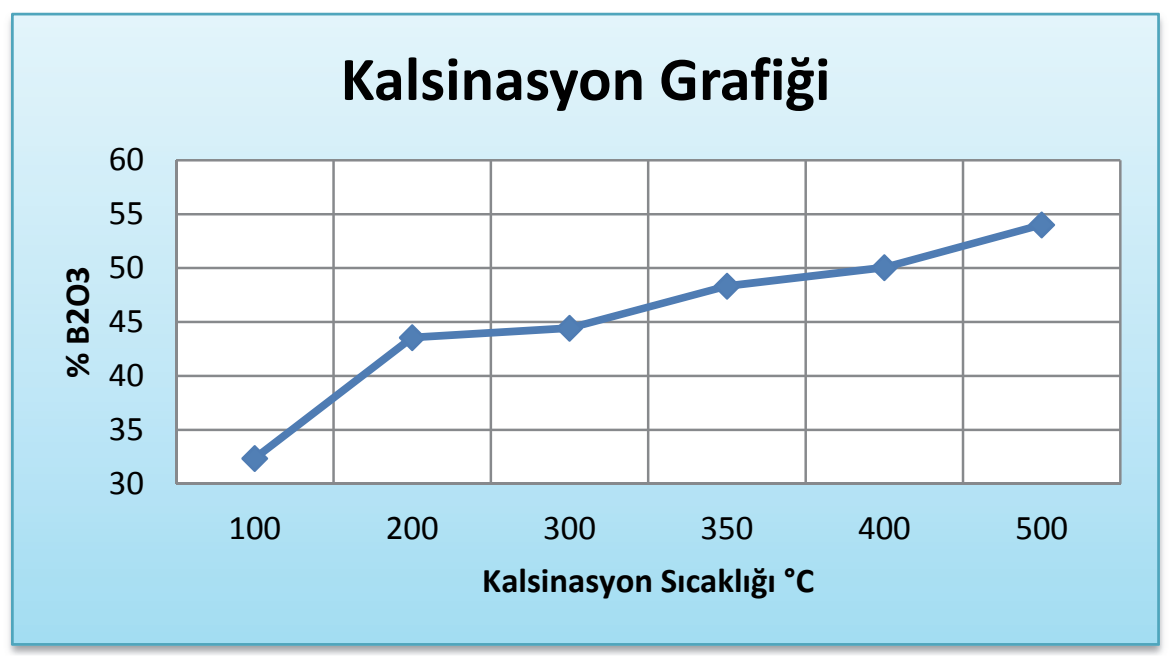

Şekil 4. Sicaklık- $\mathrm{B}_{2} \mathrm{O}_{3}$ Grafiği (Temperature- $\mathrm{B}_{2} \mathrm{O}_{3}$ Graphic) 


\subsection{Kalsine Tinkal ve Kilin Analizleri (Calcined Tincal and Clay Analysis)}

Kalsinasyon ve seperasyon sonucunda elde edilen kalsine tinkal ve kalsine kil, XRD ve TG-DTA cihazında incelenmiştir. Kalsine tinkal ve kalsine kilin XRD grafikleri Şekil 5'de verilirken, TG-DTA eğrileri ise Şekil 6'da verilmiştir.

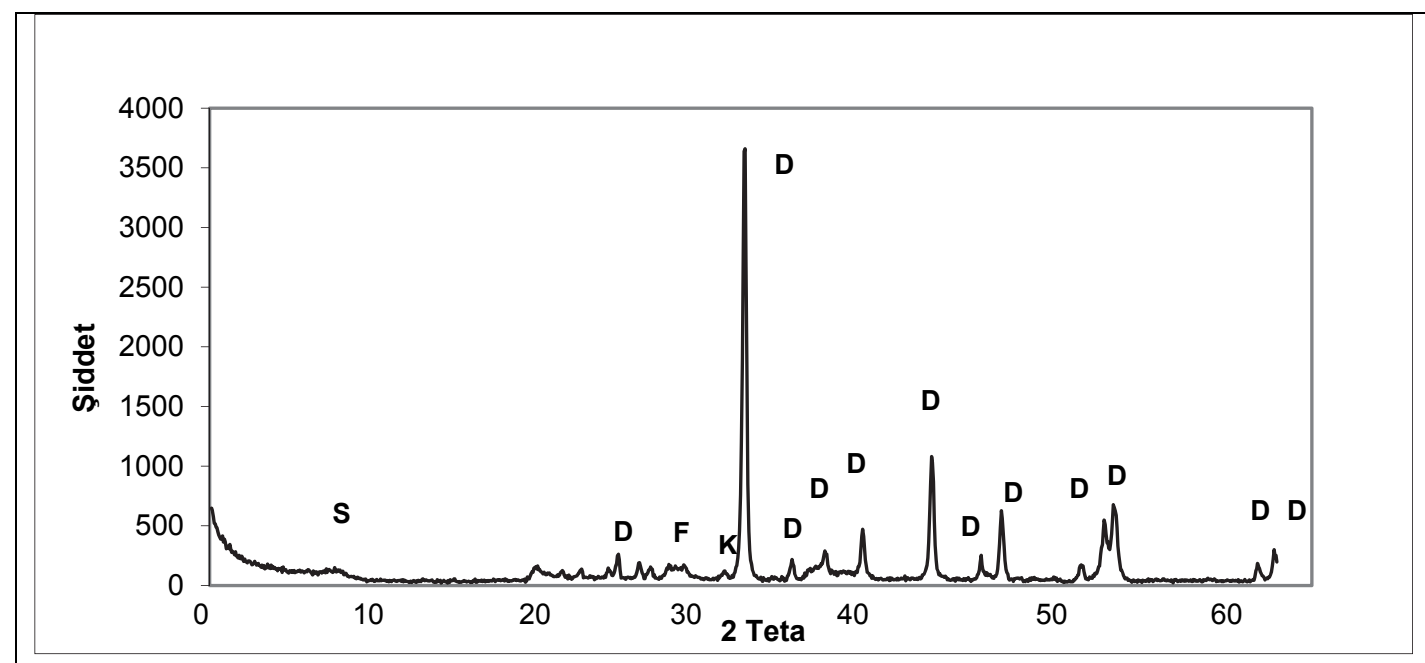

a

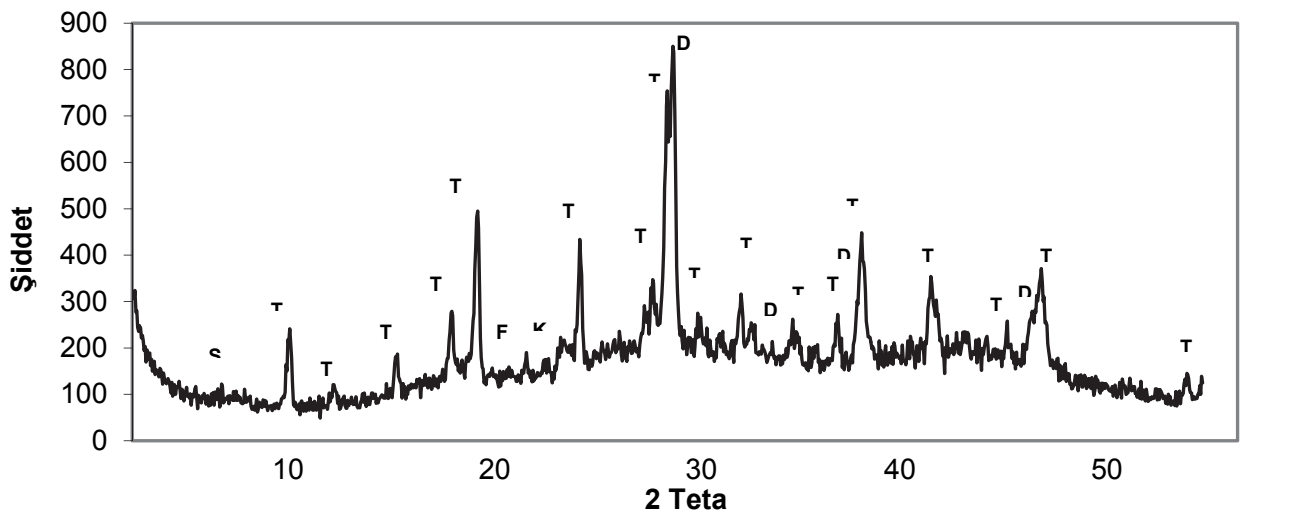

b

Şekil 5. a) Kalsine tinkal, b) kalsine kilin XRD grafikleri ( $\mathrm{T}$ : $\mathrm{Na}_{2} \mathrm{~B}_{4} \mathrm{O}_{7} \cdot \mathrm{XH}_{2} \mathrm{O}$, D: Dolomit, S: Smektit, K: Kalsit) (a) XRD Analysis of Calcined Tincal. b) XRD Analysis of Calcined Clay)

XRD grafiklerinden görüleceği üzere kalsine tinkal temel olarak boraksdan meydana gelmekte ancak boraks yanında gang mineralleri olarak dolomit, kil ve kalsit içermektedir. Kalsine kil ise temel olarak dolomit, montmorillonit tip kil (smektit) ve kalsit içermektedir. $\mathrm{Bu}$ yayında kalsine kil olarak tabir edilen kısım aslında tamamen kilden oluşmayıp belirtilen gang minerallerini içermektedir. Kil tabiri sadece isimlendirme olarak kullanılmıştır.

TG-DTA analizinde kalsine tinkalin $20-900^{\circ} \mathrm{C}$ arasında yaklaşık \%8'lik bir ağırlık kaybına uğradığ tespit edilmiş olup, bu ağırlık kaybı kalsine tinkal bünyesinde kalan sudan ve gang minerallerinin dekompozisyonundan kaynaklanmaktadır (Şekil 4). Ağırlık kaybına karşılık olarak DTA eğrisinde $150^{\circ} \mathrm{C}$ ile $700^{\circ} \mathrm{C}$ civarlarında endotermik pikler görülmüş olup, ilk pikin kaybedilen su nedeniyle, ikinci pikin ise boraksin ergimesi nedeniyle oluştuğu tahmin edilmiştir $\left(700^{\circ} \mathrm{C}^{\prime}\right.$ de ağırlık kaybı yoktur) (8). Kalsine kilde ise $600^{\circ} \mathrm{C}$ 'de yaklaşık \%30'luk bir ağırlık kaybı ve buna karşılık bir endotermik pik görülmüştür. Ağırlı kaybı, gang minerallerinde suyun kaybedilmesi ve dekompozisyon nedeniyle diğer gaz çıkışlarından kaynaklanmaktadır (8). 

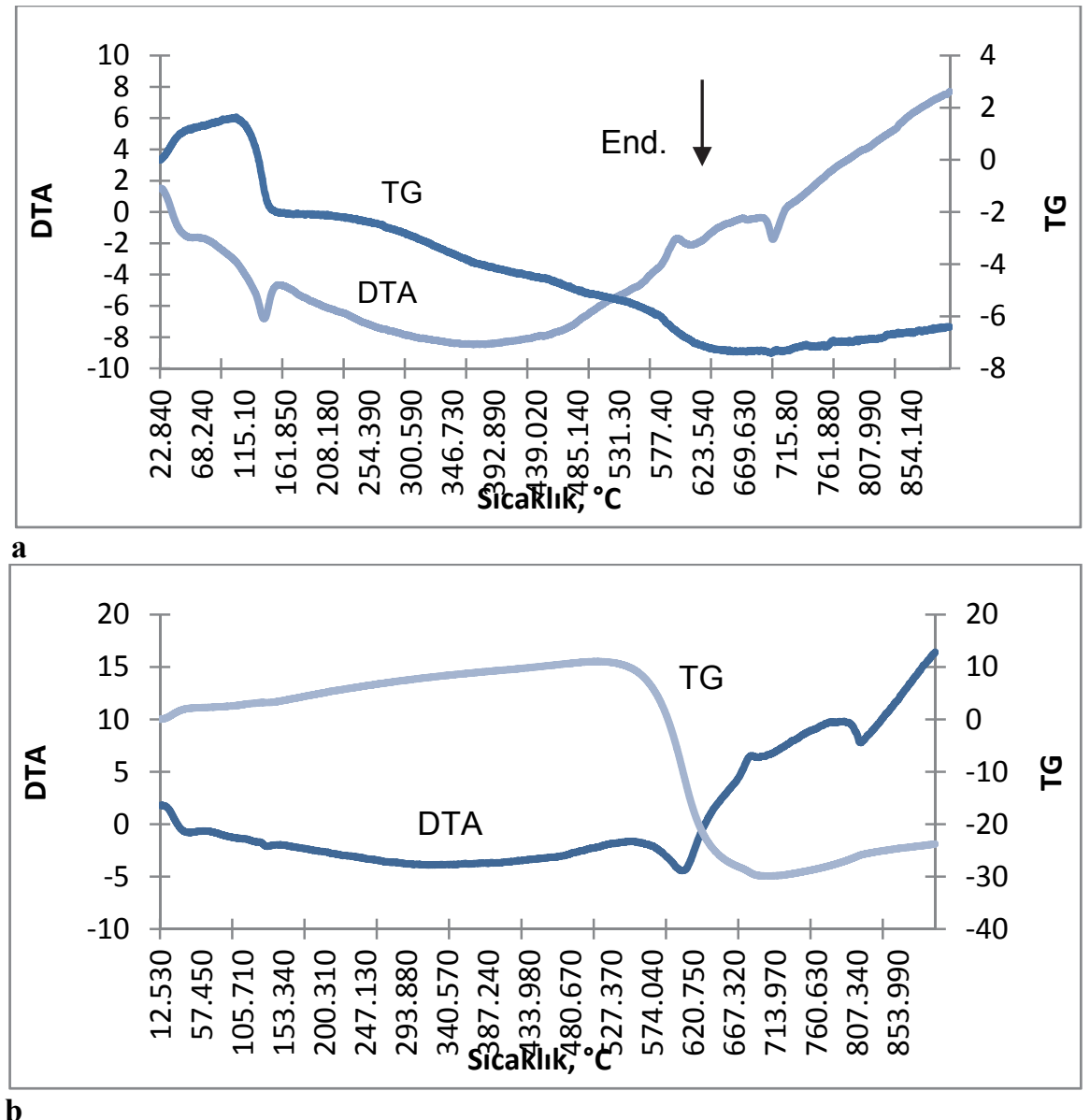

Şekil 6. a) Kalsine tinkal, b) kalsine kilin TG-DTA grafikleri (a) TG-DTA Analysis of Calcined Tincal, b) GDTA Analysis of Calcined Clay)

\section{SONUÇLAR (RESULTS)}

Tüvenan tinkalin kalsinasyonu sonucunda tinkal genleşerek daha kırılgan ve daha düşük yoğunlukta bir yapıya dönüşürken, kil ise tinkalin aksine daha sert hale gelmektedir. Tüvenan tinkalin $100-500 \quad{ }^{\circ} \mathrm{C}$ arasinda kalsinasyona tabi tutulması ile istenen oranda $\mathrm{B}_{2} \mathrm{O}_{3}$ ve kil bakımından en uygun $350^{\circ} \mathrm{C}$ 'deki çalışma belirlenmiştir. $350^{\circ} \mathrm{C}$ 'de kalsine edilen, $500 \mu$ m'ye öğütülmesi ve daha sonra seperasyonla kilin tinkal bünyesinden pnömatik seperasyonla ayrılması işlemi başarılı bir şekilde gerçekleştirilmiştir. $\mathrm{B}_{2} \mathrm{O}_{3}$ kurtarma randımanı $\% 80$ civarında elde edilen ürün $\mathrm{B}_{2} \mathrm{O}_{3}$, bünye suyu ve safsızlıklar açısından hedeflenen ürüne yakın özelliklerde bir ürün üretilmiştir. Ayrıca "Mikronize kalsine Tinkal" adı altında üretilen bu yeni ürün için patent alınmıştır $[6,7]$.

\section{KAYNAKLAR (REFERENCES)}

1- M. İ. Ünlü, M. Bilen, M. Gürü "Kütahya-Emet Bölgesi Yeraltı Sularında Bor Ve Arsenik Kirliliğ̈inin Araştırılması" J. Fac. Eng. Arch. Gazi Univ. Vol 26, No 4, 753-760, 2011,
2- U. Aydoğan, M. Bilen, M. Gürü "Anortit Seramik Malzeme Üretiminde Uçucu Kül Ve Borik Asitin Kullanılabilirliği” Gazi Üniv. Müh. Mim. Fak. Der. Cilt 26, No 4, 761-769, 2011

3- Batar, T., Kahraman, B., Cirit, E. ve Çelik, M.S., Dry Processing of Borax by Calcination as an Alternative to Wet Methods, Int. J. Miner. Process, 54, 99-110, 1998.

4- Şahin, Ö. ve Bultçu, N. 2002 "Production of High Bulk Density Anhydrous Borax in Fluidized Bed Reactor" Chemical Engineering and Processing. 41, 135-141.

5- Şahin, Ö., Genli, N., Özdemir, M. 2005 Anew Method For Producing Anhydrous Puffed Borax Chemical Engineering and Processing. 44, 1-6.

6- PCT/ IB 2007/ 054225-EP 7118803.1.“"Calcined Tincal Production method by Calcination Autogenic Grinding and Seperation (CASG) Method in a Single Step"-

7- TPE-2007/ 03372. Tek kademede Kalsinasyon Otojen Ögütme ve Seperasyon Yöntemiyle (KÖS) Kalsine Tinkal Üretimi.

8- Handbook of Chemistry and Physics, 61 Edition, CRC Pres, Florida, ABD, 1980-1981. 